\title{
Ride-hailing vs. Taxi Services: a Survey-based Comparison
}

\author{
Jiří Mezuláník \\ University of Entrepreneurship and Law, Prague, Czech Republic \\ Lukáš Durda \\ University of Entrepreneurship and Law, Prague, Czech Republic \\ Mehmet Civelek \\ University of Entrepreneurship and Law, Prague, Czech Republic \\ Lukáš Malec \\ University College of Business in Prague, Prague, Czech Republic
}

Received: 12 May 2020. Revision received: 31 May 2020. Accepted: 12 June 2020

\begin{abstract}
As being an important player of sharing economy, ride sourcing services provide benefits for socioeconomic and environmental issues of countries and make positive contributions for sustainability. To indicate socioeconomic and environmental influences of these services, this paper aims to make comparison between some alternative Transportation Network Companies, namely, Taxify, Uber and Liftago and standard taxi services regarding their drivers', vehicles' and trips' characteristics. In line with this objective, this research investigates 84 drivers of ride sourcing services and standard taxi industry from two various cities of the Czech Republic, namely, Prague and Ostrava. The data of this paper was collected by using a self-administered questionnaire and the researchers applied multiple correspondence analysis in R-software to make the analyses of this research. The results of these analyses show that different from standard taxi services, most of the drivers of Taxify in Prague are not Czech fluent. Moreover, in Prague, drivers of Uber Technology Network company work at the weekends and they drive Uber cars as a part time work. When it comes to transportation activities in Ostrava, standard taxi services were driven for higher kilometres and at the weekends, while total kilometres that were driven by Liftago's cars are less than standard taxi services and these trips were mostly taken in workdays. These results show that services of standard taxi industry and ride sourcing services differ regarding characteristics of drivers, trips, vehicles, passengers and cities. Some policy implementations are also provided by this paper to hinder disruptive transportation actions.
\end{abstract}

Key Words: platform economy, ride-hailing, ridesharing, ride-sourcing, sharing economy, transportation industry, Uber

JEL Classification: L91, O18, O33

Reference: Mezuláník, J., Durda, L., Civelek, M. \& Malec, L. (2020). Ride-hailing vs. Taxi Services: a Survey-based Comparison. Journal of Tourism and Services, 20(11), 170-186. doi: 10.29036/jots.v11i20.155

\section{Introduction}

Technological developments and innovations have created a new economic phenomenon, namely sharing economy that has provided many chances for businesses including firms that work in transportation industry. Sharing economy is identified as a peer to peer activities that enable to purchase and sale of good and services via online platforms that use information technologies, where the key element is the sharing of private assets by individuals (Ključnikov et al., 2018; Bencsik et al., 2019). The aim of this approach is to use or consume idle resources collaboratively (Cheng et al., 2018). Moreover, 


\section{JOURNAL OF TOURISM AND SERVICES}

Issue 11, volume 20, ISSN 1804-5650 (Online)

www.jots.cz

owners of these sharing economy platforms make vendors and purchasers to communicate between each other (Cheng et al., 2018; de Souza Silva et al., 2018; Belk, 2014; Hamari et al., 2016; Cheng et al., 2018). These owners are freer to access to markets due to having less barriers via online platforms. Moreover, they have easier registration conditions as they not have to have some certifications from governments (Cheng et al., 2018).

As being a good example of sharing economy platform, ride sourcing services have been operating since 2009 by serving door to door transportation options (de Souza Silva et al., 2018). Uber is the first and leading platform in a ride sharing industry. Taxify, Liftago, Cabify, Lyft, Didi and Sidecar are some of the other examples of ride sourcing and hailing services. As trends in their usage rapidly increase all over the world, their usage in the Czech Republic also rise especially in bigger cities for instance, Prague and Ostrava. Total population in both of those cities is more than 1.5 million. As trends in their usage rapidly increase all over the world, their usage in the Czech Republic also rise especially in bigger cities for instance, Prague and Ostrava. Total population in both of those cities is more than 1.5 million. Prague is very attractive city for foreign and domestic tourists due to having special historical monuments and buildings and other catchy opportunities for visitors. Ostrava is gaining growing popularity among tourists in the last years, especially with its industrial monuments and cultural events. As being a convenience transportation option not only for citizens but also for also tourists, ride sourcing platforms also provide many benefits for visitors. Therefore, analysing ride sourcing and taxi industry in the Czech Republic can make policy makers, governments, practitioners and owner of ride sourcing platforms, other transportation providers and users of these services to be interested with the results of this study. Furthermore, academicians can also gain benefits from the findings of this research.

Ride sourcing services are usually got by users for their trips that are not done regularly (Brown, 2018; Grahn et al., 2019; Tirachini \& del Rio, 2019). This is because when it comes to longer trips with more kilometres, passengers prefer travelling with public transport (Tirachini \& del Rio, 2019). Availability of public transport, and weather conditions are also other facts that might change preferences of individuals to use ride sourcing services (Chen et al., 2017; Etminani-Ghasrodashti \& Hamidi, 2019). The competition among standard taxi services and ride sourcing services weakens monopoly power of traditional taxi services and makes standard taxis to improve their services to compete with ride sourcing (de Souza Silva et al., 2018). This fact enables passengers of these services to have more qualified trips and influences their choices regarding the type of transportation.

Except from competition among transportation providers, features of these services also influence individuals' transportation decisions. In this regard, security (Young \& Farber, 2019; Rayle et al., 2016; Schaller, 2018; Tirachini \& Gomez-Lobo, 2019; Etminani-Ghasrodashti \& Hamidi, 2019), waiting time (Rayle et al., 2016; Young \& Farber, 2019), travel time (Young \& Farber, 2019; EtminaniGhasrodashti \& Hamidi, 2019; Rayle et al., 2016), flexibility (Etminani-Ghasrodashti \& Hamidi, 2019; Rayle et al., 2016), cost (Young \& Farber, 2019; Etminani-Ghasrodashti \& Hamidi, 2019; Rayle et al., 2016), convenience (Young \& Farber, 2019; Schaller, 2018; Tirachini \& Gomez-Lobo, 2019), paymet method (Rayle et al., 2016; Schaller, 2018; Tirachini \& Gomez-Lobo, 2019), comfort (Rayle et al., 2016; Schaller, 2018; Tirachini \& Gomez-Lobo, 2019) and service quality (Schwieterman \& Smith, 2018) of these services are determinant factors that affect customers' behaviours regarding transportation.

Transportation choices of passengers also differ regarding their propensity to use new technologies, their behaviours and socio-economic features (Etminani-Ghasrodashti \& Hamidi, 2019; Rayle et al., 2016). In this regard, some studies consider these factors and analyse the differences between age, (Young \& Farber, 2019; de Souza Silva et al., 2018), gender(Etminani-Ghasrodashti \& Hamidi, 2019; de Souza Silva et al., 2018; Young \& Farber, 2019), level of education (Rayle et al., 2016; de Souza Silva et al., 2018; Etminani-Ghasrodashti \& Hamidi, 2019) and level of income (Clewlow \& Mishra, 2017; Schwieterman \& Smith, 2018; Etminani-Ghasrodashti \& Hamidi, 2019). Instead of passengers' characteristics, this research considers drivers' characteristics that might create significant values for related literature. 


\section{JOURNAL OF TOURISM AND SERVICES}

Issue 11, volume 20, ISSN 1804-5650 (Online)

www.jots.cz

Drivers of these services have more autonomy since they can make their own decisions to participate and provide ride sourcing activities (Wang et al., 2018). They usually make these decisions regarding incomes that they will get from offering these services (Chen \& Sheldon, 2017). Drivers also have flexible working hours that depends on their availability (Cheng et al., 2018). Most of the drivers of ride sourcing platforms are part time workers, drive their own car with no licensed plate as traditional taxi services have, and do not hold commercial driver license as traditional taxicab drivers have (Rayle et al., 2016; Schwieterman \& Smith, 2018). Working hours of drivers of these services might influence prices because supply and demand for ride sourcing services can change.

Some studies compare various transportation providers such as public transport, traditional taxis and a ride sourcing service (Tirachini \& del Rio, 2019; Young \& Farber, 2019; Rayle et al., 2016; de Souza Silva et al., 2018; Etminani-Ghasrodashti \& Hamidi, 2019). Other researches also compare public transportation, travelling by car and ride sourcing services (Hyland et al., 2017; Schwieterman \& Smith, 2018). Rayle et al. (2016) also make comparisons between ride sourcing and ride splitting services and state that ride sourcing differs from ride splitting because drivers of ride sourcing platforms aim to increase their income and trips that they provide are not their own trips depends on customers' request. But this research includes more ride sourcing platforms into analyses and compare them with standard taxi services.

Type of car, technology, driver characteristics and service quality (features of trips) are other factors that can affect competitiveness of different transportation providers. In this regard, different from above mentioned studies, this research aims to draw attentions to the importance of drivers', travels' and cars' characteristics for transportation industry of the Czech Republic by comparing these services in both cities Prague and Ostrava. In line with this selected purpose, research questions might arise as follows: Do differences exist between mileage (higher and lower), car identification (yes or no), car manufacturer, frequency of daily trips (workday or weekend), type of work (part time-full time) and language fluency (yes, no) in the services of alternative platforms and standard taxi services?

\section{Literature review}

Ride sourcing is a transportation platform that provides online connection between drivers and travellers to perform passengers' requested trips (Schwieterman \& Smith, 2018). The technology that ride sourcing platforms use not only enables its users to have up to date information about the details of their journey but also easier conditions to make their payments for their specified trips (Young \& Farber, 2019). People who are more interested in technologies and are more informed about applications of ride sourcing services are more prone to travel with a car fleet of these transportation providers instead of using public transportation options (Etminani-Ghasrodashti \& Hamidi, 2019).

Security of these web-based platforms and quick reaction of other parties (drivers) are important factor that affect quality of ride sourcing services because these factors influence pleasure and loyalty of passengers (Cheng et al., 2018). When hailing a driver, ride sourcing users take different steps via online platforms such as making reservation, payment, and rating to drivers by their mobile devices (Cheng et al., 2018; Schwieterman \& Smith, 2018). This fact also has made them to substitute for taxi services. Moreover, some individuals also prefer having trips with ride sourcing services instead of travelling with their own car, or public transport options. However, when potential users perceive some problems regarding security of these services, they look for choices of other transportation providers (EtminaniGhasrodashti \& Hamidi, 2019).

In reservation process, passengers send a request by remarking route of their trip via applications and then the applications match drivers and passengers depending on their location and select closest drivers for potential travellers (Etminani-Ghasrodashti \& Hamidi, 2019). After that, passengers see the price that these platforms offer in a real time (Etminani-Ghasrodashti \& Hamidi, 2019; Sun et al., 2019; 


\section{JOURNAL OF TOURISM AND SERVICES}

Issue 11, volume 20, ISSN 1804-5650 (Online)

www.jots.cz

Schwieterman \& Smith, 2018; Rayle et al., 2016). When passenger accept the price of a selected driver, applications ask to the driver to confirm the trip or not. After this confirmation, travellers can see when the driver arrives to specified location and finally depending on duration of waiting, passengers make decision to travel (Etminani-Ghasrodashti \& Hamidi, 2019). Then, they make a payment for their trips and after completing trips they rate ride sourcing services that they have got.

Due to having less frequent trips of public transportation at late hours and evenings, travelling with ride sourcing services usually happens at these late hours of Friday and Saturday (Tirachini \& del Rio, 2019; Young \& Farber, 2019; Rayle et al., 2016). Ride sourcing services reduces drunk-driving (Young \& Farber, 2019; Tirachini \& del Rio, 2019). Furthermore, people do not waste their time when using ride sourcing services because they do not need to look for a parking space as they do for their own car (Young \& Farber, 2019; Tirachini \& del Rio, 2019). Passengers become less likely buy their own cars (Rayle et al., 2016; Henao, 2017; Henao \& Marshall, 2017; Tirachini \& del Rio, 2019; de Souza Silva et al., 2018). Thus, number of the cars in the traffic might be decreased (Tirachini \& del Rio, 2019) and traffic congestion might be reduced by using ride sourcing services (Etminani-Ghasrodashti \& Hamidi, 2019; Santi et al., 2014).

When the number of people who live together increases their propensity of using ride sourcing services decrease. This is because they prefer travelling with their own car (Etminani-Ghasrodashti \& Hamidi, 2019). Most of users travel with ride-hailing services for their leisure, recreational activities (Rayle et al., 2016; Clewlow \& Mishra, 2017; Henao, 2017, de Souza Silva et al., 2018; Young \& Farber, 2019), and social activities (Rayle et al., 2016; Young \& Farber, 2019) and also when they go back to their home or going to their work (Rayle et al., 2016).

When it comes to competition among transportation providers, fleet sizes, pricing policies and regulations that transportation providers face carry high importance in the competition between them (Qian \& Ukkusuri, 2017; Sun et al., 2019). Waiting time is another significant indicator that influences competition between players of transportation (Rayle et al., 2016; Androniceanu \& Tvaronavičiené, 2019). This is because, all those factors influence passengers' travel expenses and their waiting period (Rayle et al., 2016; Qian \& Ukkusuri (2017; Sun et al., 2019).

Traditional taxi services are under some strict regulations regarding their safety (Young \& Farber, 2019; Rayle et al., 2016; Etminani-Ghasrodashti \& Hamidi, 2019) and their price tariffs are also set by policy makers (Rayle et al., 2016; Young \& Farber, 2019; Sun et al., 2019). Moreover, they have to get license templates and the number of these template is limited. On the other hand, ride sourcing services do not face with such conditions (Cohen \& Shaheen, 2016; Young \& Farber, 2019). Applied technologies by ride sourcing services make them to be distinguished from traditional taxi services (Rayle et al., 2016; de Souza Silva et al., 2018) that still use their taxi hailing systems or street hailing. This is one the reasons why traditional taxi services lose their power in the competition between ride sourcing services (Rayle et al., 2016).

Prices of trips are not fixed because it depends on length of trips and traffic conditions (Sun et al., 2019; Schwieterman \& Smith, 2018). For instance, when passenger request a trip at rush or late hours, rises can be occurred in prices (Schwieterman \& Smith, 2018). But as they do not have set price tariffs, they can provide cheaper services for their passengers and this fact is one of the reasons why users of ride sourcing platforms prefer having trips with these services instead of traditional taxi services (Enoch et al., 2004; Etminani-Ghasrodashti \& Hamidi, 2019; de Souza Silva et al., 2018). This fact causes increases in the number of trips of ride sourcing platforms decreases in the number of trips of traditional taxi services (Young \& Farber, 2019).

Corresponding to the differences in duration of journey, waiting period and travel time of ride sourcing services are also shorter than traditional taxi services (Rayle et al., 2016; Etminani-Ghasrodashti \& Hamidi, 2019; Sun et al., 2019). Thus, ride sourcing drivers can have more trips and travel with more passengers than traditional taxi services (Rayle et al., 2016). Another important factor that ride sourcing differs from taxi services is passengers can only hail ride sourcing services by an online platform or an 


\section{JOURNAL OF TOURISM AND SERVICES}

Issue 11, volume 20, ISSN 1804-5650 (Online)

www.jots.cz

application instead of street hail. Thus, passengers can only use these services when they arrange their journey via web and an application (Schwieterman \& Smith, 2018). According to Schwieterman and Smith (2018), when people travel with ride sourcing services, they can arrive their destination earlier and save their time because of non-existence of direct public transport in their routes can make them to walk or to transfer for another vehicle that cause them to waste their times. Therefore, passengers have shorter trips when travelling with ride sourcing services in comparison with other transportation providers such as public buses, metro lines and railways (Etminani-Ghasrodashti \& Hamidi, 2019).

For these reasons, ride sourcing services substitute for traditional taxi services and public transport (de Souza Silva et al., 2018; Tirachini \& del Rio, 2019). Public transport market share is declining (Poliak et al., 2017) and ride sourcing plays complementary role for public transport since some of passengers use these services to transfer to other transportation options such as buses, railways and metro lines. (Rayle et al., 2016; Etminani-Ghasrodashti \& Hamidi, 2019). Etminani-Ghasrodashti and Hamidi (2019) also clarify that a positive relationship exists between the number of metro stations in a region and the number of requested travels in ride sourcing services. These researchers also explain the fact that the number of requested travels is also positively related with the number of people who live in a specific region. On the other hand, when there is lack of options to travel with public transport in a region, individuals become more interested to having trips with ride sourcing services.

In comparison with traditional taxi services, passengers of ride sourcing services are usually male, (de Souza Silva et al., 2018), younger (Young \& Farber, 2019; de Souza Silva et al., 2018), highly educated, (Rayle et al., 2016; de Souza Silva et al., 2018; Etminani-Ghasrodashti \& Hamidi, 2019) and have more income (Clewlow \& Mishra, 2017; Schwieterman \& Smith, 2018 ; Etminani-Ghasrodashti \& Hamidi, 2019), ride-hailing services are generally safer for women passengers than traditional taxis (EtminaniGhasrodashti \& Hamidi, 2019).

As previously stated, some of the main reasons why users prefer travelling with ride sourcing services are related with comfort (Tirachini \& del Rio, 2019), safety (Tirachini \& del Rio, 2019; de Souza Silva et al., 2018) cost (Schwieterman \& Smith, 2018; Tirachini \& del Rio, 2019; de Souza Silva et al., 2018), reduced travel time (Tirachini \& del Rio, 2019) and quality of these services (Schwieterman \& Smith, 2018). The quality of services that ride sourcing platforms provide also depends on drivers' attitudes to their passengers. Therefore, ride sourcing platforms enable their users to rate their drivers' performance (McGregor et al., 2016; Lee et al., 2015, p. 1603; Raval \& Dourish, 2016; Rosenblat \& Stark, 2016). This fact makes practitioners of these platforms to improve service quality of ride sourcing activities by warning and giving some recommendations to their underperformer drivers for enhancement of these drivers' performance (Rosenblat et al., 2017; Štefko, 2019). Since drivers are aware of fact that they are rated by their passengers, they offer better services than traditional taxicab drivers (McGregor et al., 2016; Campbell, 2015) to have more income and to get higher-paid trips. For instance, Uber has an incentive mechanism that sometimes provides high rated drivers to have guaranteed high hourly income (Rosenblat et al., 2017).

Moreover, giving exact information, competency and being able to understand passengers' feelings make drivers of ride sourcing services to provide better service quality for their passengers. These attitudes make customers to be more satisfied and engaged with these services (Cheng et al., 2018). In this regard, having fluent drivers in these services also important factor to increase service quality. This is because Czech fluent drivers might be more able to have better communication with their passengers and increase their service quality. Except from attitudes, racial, sex, nationality of drivers might also influence the ratings of drivers (Castilla, 2008; Rosenblat et al., 2017). For instance, Wang et al. (2015) analyse Airbnb hosts and find that incomes of Asian hosts are lower than other hosts that have different nationality. Since most of Czech fluent drivers might be Czech, their ratings might be higher than other drivers who are not Czech. On the other hand, Etminani-Ghasrodashti and Hamidi (2019) find that drivers of traditional taxi services perform better in rush hours and in traffic jam than drivers of ride sourcing services since they have more experience and not being up to GPS. 


\section{JOURNAL OF TOURISM AND SERVICES}

Issue 11, volume 20, ISSN 1804-5650 (Online)

www.jots.cz

Except attitudes of drivers, characteristics of trips and vehicles also might determine service quality of these platforms. Due to having frequent trips, cars that are driven by ride sourcing drivers have more kilometres (Clewlow \& Mishra, 2017; Schaller, 2018; Henao \& Marshall, 2018; Erhardt et al., 2019; Tirachini and Gomez-Lobo, 2019). Furthermore, size of cars that they provide is also important since a group of people might use larger cars to travel and might hail a large car from a ride sourcing provider instead of going by public transport (de Souza Silva et al., 2018). Models of cars in fleet of transportation providers also can change passengers' perceptions about quality of services, thus, it might influence customers' travelling decisions.

\section{Data and Methodology}

This study used questionnaire survey to collect data and the respondents of this survey were the drivers of alternative taxi and standard services. To select to the respondents, the researchers applied random sampling method, and then some students of two universities collected data in 2017. A selfadministered questionnaire was directed to respondents who were from Prague and Ostrava and this questionnaire included closed-ended questions. The investigated variables in this research are providers of transportation services (Uber, standard taxi service, Taxify and Liftago), car manufacturers, mileage (higher and lower), car identification (binary variable, yes and no), frequency of trips in different days (workday or weekend), drivers' employment types (for main employment or extra) and drivers' ability to speak Czech language (Czech fluent or not). The mileage is categorized as higher and lower depending on kilometres that each car has been driven respectively, more than $200000 \mathrm{~km}$ and less than 200000 $\mathrm{km}$.

Although numerical variables can be generally handled as additional and divided into the categories for highlighting nonlinear associations, the researchers of this study identified them as untransformed. This is the case of one variable income derived simply from the others as daily mileage, general taxi and starting taxi rates. After excluding the respondents that had missing values in the questionnaires, 57 respondents from Praha and 27 respondents from Ostrava are taken into consideration for the analyses. Due to facing difficulties to collect the data, the study has relatively small samples, thus, the researchers do not exclude outliers.

Frequency statistics of the samples of Ostrava and Prague are presented in Table 1. Different from Prague, there are two different transportation providers in Ostrava, namely standard provider and Liftago. Moreover, car identification variable is not in existence in the table of Ostrava because only nonidentified cars are registered. It was proved that income variable has no connection with other variables. All of the respondents from Ostrava are male and mostly Czech fluent. The most of the cars' brands are Škoda and Volkswagen and Ford. Most of the drivers provide these services as their main activities at workdays. Some of the variables are excluded from analyses because they are not proper as they are highly correlated with each other (e.g. calling the vehicle, age of the drivers, most common time and gender). 


\section{JOURNAL OF TOURISM AND SERVICES}

Issue 11, volume 20, ISSN 1804-5650 (Online)

www.jots.cz

Table 1. Frequency Table for Prague and Ostrava

\section{Prague}

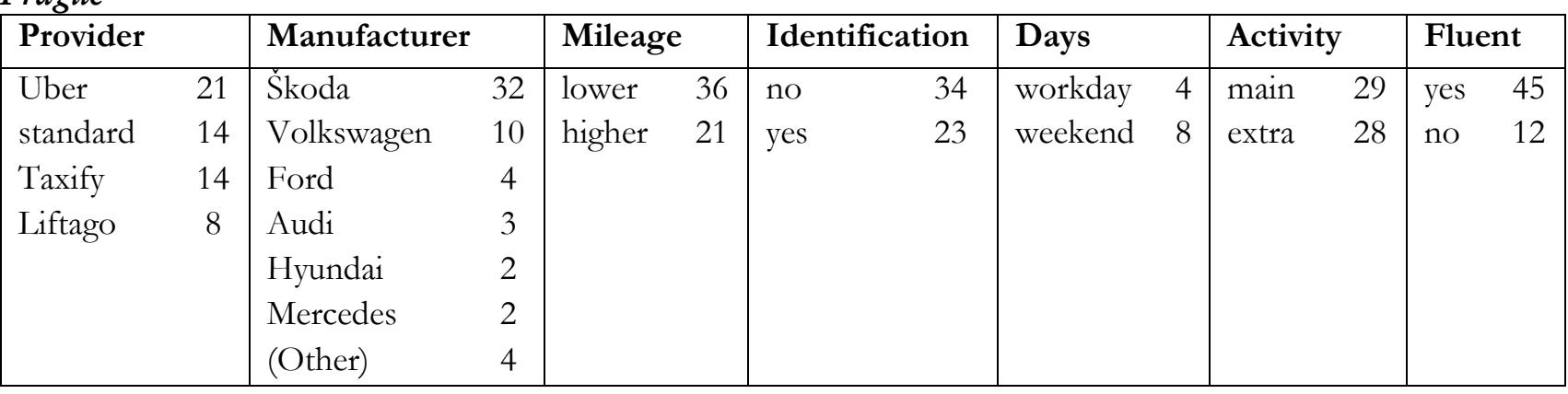

\section{Ostrava}

\begin{tabular}{|lc|lc|lc|lc|lc|}
\hline Provider & & Manufacturer & & Mileage & Days & & \multicolumn{2}{|l|}{ Activity } & \\
\hline standard & 16 & Škoda & 14 & higher & 16 & workday & 21 & main & 24 \\
Liftago & 11 & Volkswagen & 5 & lower & 11 & weekend & 6 & extra & 3 \\
& & Peugeot & 4 & & & & & & \\
& & Ford & 2 & & & & & & \\
& & (Other) & 2 & & & & & & \\
\hline
\end{tabular}

Source: own compilation

Multivariate approach of the correspondence analysis proved to be suitable for our data processing situation where first two dimensions fit the inputs well. Multiple correspondence analysis is a type of geometric data analysis (Le Roux \& Rouanet, 2004) and can be handled as multivariate statistical technique. The multiple correspondence analysis (Husson et al., 2009; Kassambara, 2017) was used to process the categorical data with one extension of quantitative variable not incorporated directly into computations. Although the results can be interpreted similarly to better known principal component analysis and other statistical methods (Bílková, 2017), it enables to simultaneously describe the relations within the groups of variables, individuals (observations) as well as categories of variables.

As noted by Husson et al. (2009), such analysis is a specific application of correspondence analysis for more than two variables and searched dimensions (new variables as components) summing the information for whole dataset. We primarily focus on categories for mutual presenting original variables and a group of individuals. First dimension is most important in explaining the relations between variables. The next one is the second most important, and so on, covering the maximum variation criterion (Le Roux \& Rouanet, 2004). The computations are based on finding modified eigenvalues of the input contingency-based matrices which expressed the correlations of variable with individual dimensions. Also, relations between variable categories are complemented in squared cosine $(\cos 2)$ metric indicating significance of dimension for a given category (Abdi \& Lynne, 2010). Confidence ellipses around the mean point of categories are depicted in the visualizing only individuals. The computations were performed in R-software ( $\mathrm{R}$ Development Core Team, 2019) using packages FactoMineR and factoextra.

We express the results in two-dimensional Cartesian coordinate system. It is usual to interpret the multiple correspondence analysis in more dimensions than principal component analysis. Despite to this fact, first two dimensions describe enough information in our case and we express such relations graphically as well as in tabular form. The categories are represented at the barycentre of the individuals as this is executed by maximising the variation of the cloud of categories on the system of orthogonal axes by homothetic transformations. But the variation of the category increases if the category is rare so under-represented categories should be handled with care. It is desired to group certain categories 


\section{JOURNAL OF TOURISM AND SERVICES}

Issue 11, volume 20, ISSN 1804-5650 (Online)

www.jots.cz

together or randomly distribute the individuals associated with rare categories to other categories where we select the first mentioned approach. When a variable has large number of categories, these categories are shared over many different dimensions as number of dimensions equals number of categories minus one. In this case, this variable does not systematically influence construction of the dimensions. On the other hand, the $p$-values of individual tests covering input variables and categories are introduced exclusively for first dimensions in tabular form.

\section{Results and discussion}

Steady decrease of eigenvalues magnitude is visible from the both scree plot graphs covering Fig. 1 with sharp decline between first and second dimensions introducing the first as dominant in both cases. However, first two dimensions bring enough information to describe relations especially for Ostrava with almost $60 \%$ of explained variation in data.

Figure 1. Scree plots
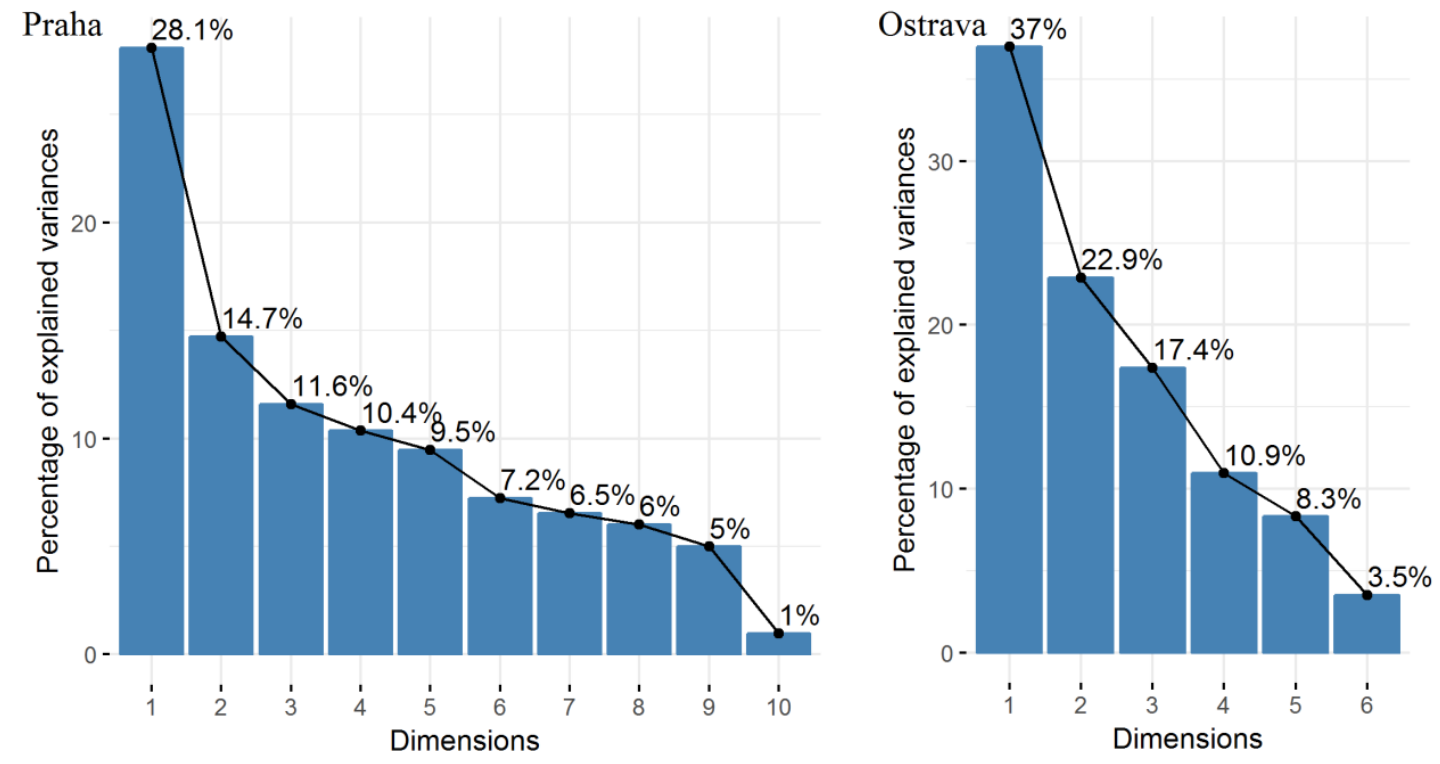

Source: own compilation

The graph of the cloud of variables (Fig. 2) is represented by correlation ratios expressed as coefficients of determination between coordinates of individuals on one component and each of the categorical variables. This serves to identify relation to dimension, but the structure also reveals the representation of categories. It can be seen that majority provider scores high on both dimensions while car identification only on the first in Praha. Covering Ostrava, car manufacturer is highly correlated on both dimensions while majority provider and mileage is important only for the first dimension. Rather, we concentrate our attention on the phenomena at hand for its relation to derived variable income. Almost no connection found for this variable regarding economic balance of the problem. 
JOURNAL OF TOURISM AND SERVICES

Issue 11, volume 20, ISSN 1804-5650 (Online)

www.jots.cz

Figure 2. Structural variable correlations with additional variable
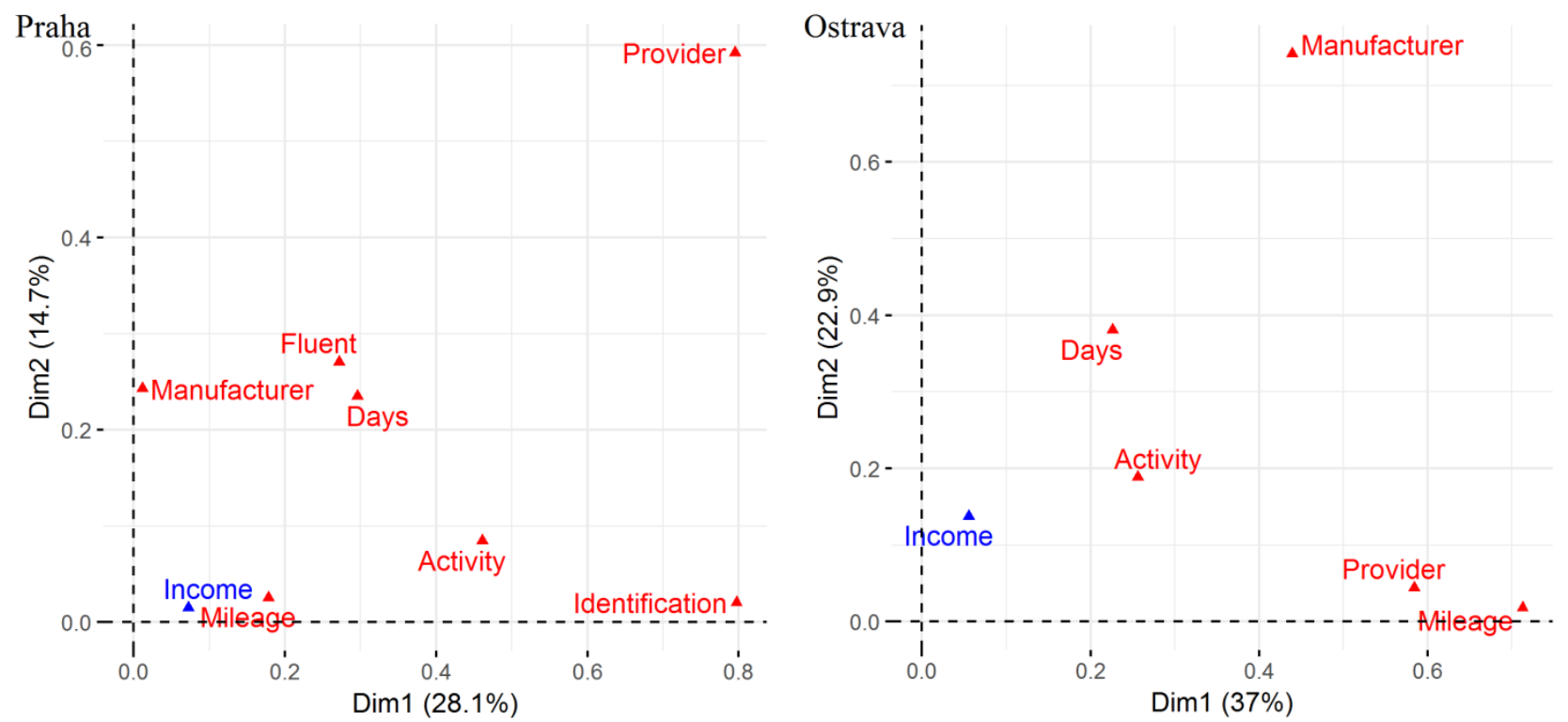

Source: own compilation

In Table 2, the determination coefficient $p$-values of the corresponding $F$-tests are introduced for expressing the most joined original variables with a given dimension. Although such relational patterns are biased, it serves as a tool for selecting the most important items and inductive quantification of relations demonstrated above.

Table 2. Variables relation to first dimension

\begin{tabular}{|ll|ll|}
\hline Praha & & Ostrava & \\
\hline Variables & $p$-value & Variables & $p$-value \\
\hline Identification & $1.07 \mathrm{e}-20$ & Mileage & $3.12 \mathrm{e}-08$ \\
Provider & $3.05 \mathrm{e}-18$ & Provider & $3.51 \mathrm{e}-06$ \\
Activity & $6.37 \mathrm{e}-09$ & Manufacturer & $9.60 \mathrm{e}-04$ \\
Days & $1.24 \mathrm{e}-05$ & Activity & $7.05 \mathrm{e}-03$ \\
Fluent & $3.26 \mathrm{e}-05$ & Days & $1.22 \mathrm{e}-02$ \\
Mileage & $1.06 \mathrm{e}-03$ & & \\
\hline \multicolumn{4}{|l}{ Source: own compilation } \\
\hline
\end{tabular}

The next step is to reveal target relational pattern of the categories under study. Two categories are considered close each other the more individuals they have in common, and vice versa. Using squared cosines, we are able to better evaluate the relationships significance using colour palette. Covering Fig. 3 , in Praha, decisive variable is car identification. Nonidentified cars are positively related to providers Uber and Taxify. Other variables are also positively related to car identification where no Czech fluent is joined to Taxify as Uber relates to weekend prevailing days and extra driver activity. On the other hand, identified cars are often members of standard taxi covering main employment of Czech fluent driver working rather at workday. Although, the positive relation of Liftago provider is significant on the first dimension, it should be handled with caution for small value of $\cos 2$. In Ostrava, the number of variables is decreased. Here, higher mileage is positively joined to standard taxi operated at weekend and moreover concentrated on Volkswagen cars. It seems Škoda manufacturer is used by drivers during weekend 


\section{JOURNAL OF TOURISM AND SERVICES}

Issue 11, volume 20, ISSN 1804-5650 (Online)

www.jots.cz

opposite to Volkswagen. On the other hand, lower mileage is positively related to Liftago provider and more in workday jobs. Again, other manufacturer and main job should be interpreted with caution on first two dimensions explained.

Figure 3. Categories representation
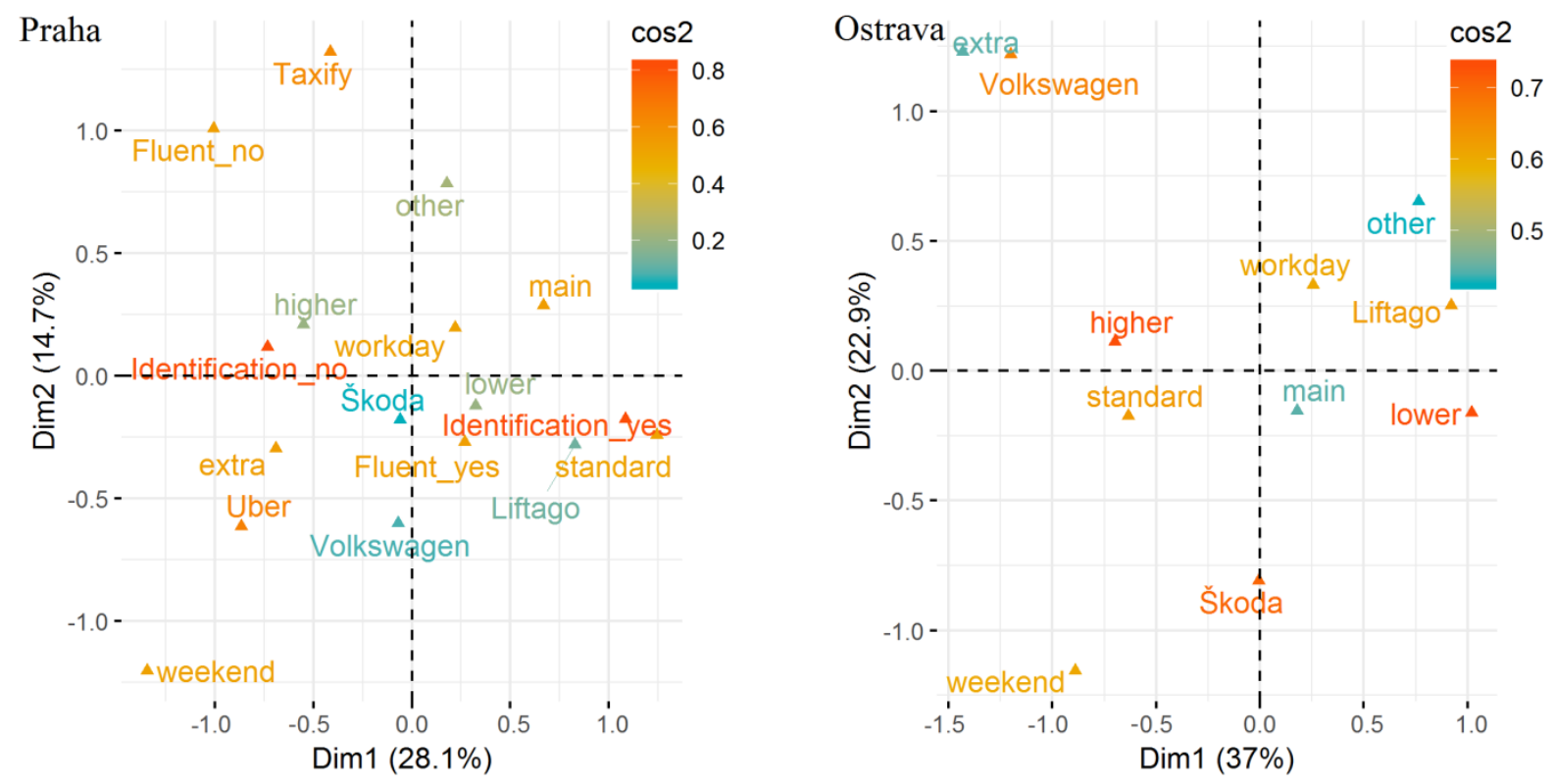

Source: own compilation

In case of well presentation of variable category in two dimensions, the sum of $\cos 2$ is close to one. Although the first two dimensions are the most important in explaining variations within the data, it can be seen for some categories that they should be presented in more dimensions.

Table 3. Categories relation to first dimension

\begin{tabular}{|c|c|c|c|}
\hline \multicolumn{2}{|l|}{ Praha } & \multicolumn{2}{|l|}{ Ostrava } \\
\hline Categories & $p$-value & Categories & $p$-value \\
\hline Identification_no & $1.07 \mathrm{e}-20$ & higher & $3.12 \mathrm{e}-08$ \\
\hline Extra & $6.37 \mathrm{e}-09$ & standard & $3.51 \mathrm{e}-06$ \\
\hline Uber & $1.95 \mathrm{e}-08$ & Volkswagen & $1.82 \mathrm{e}-03$ \\
\hline Weekend & $1.24 \mathrm{e}-05$ & extra & $7.05 e-03$ \\
\hline Fluent_no & $3.26 \mathrm{e}-05$ & weekend & $1.22 \mathrm{e}-02$ \\
\hline higher & $1.06 \mathrm{e}-03$ & workday & $1.22 \mathrm{e}-02$ \\
\hline Liftago & $1.11 \mathrm{e}-02$ & other & $8.58 \mathrm{e}-03$ \\
\hline lower & $1.06 \mathrm{e}-03$ & main & $7.05 e-03$ \\
\hline Fluent_yes & $3.26 \mathrm{e}-05$ & Liftago & $3.51 \mathrm{e}-06$ \\
\hline workday & $1.24 \mathrm{e}-05$ & lower & $3.12 \mathrm{e}-08$ \\
\hline main & $6.37 \mathrm{e}-09$ & & \\
\hline standard & $6.56 \mathrm{e}-10$ & & \\
\hline Identification_yes & $1.07 \mathrm{e}-20$ & & \\
\hline
\end{tabular}




\section{JOURNAL OF TOURISM AND SERVICES}

Issue 11, volume 20, ISSN 1804-5650 (Online)

www.jots.cz

The correlation coefficient $p$-values of the $t$-tests for expressing the most joined categories with a given dimension are introduced in Table 3. Here, they are arranged from the positive ones of greatest magnitudes to the lowest valued in individual columns.

Next, we study the relations of individuals covering only Prague depicting variables major provider and car identification (Fig. 4). We draw the confidence ellipses around the categories. These ellipses can be used to plane representations covering visualisation of significant difference of the categories. This confirms the assumption of similar behaviour of Taxify and Uber for no identification while standard taxi for identified cars. Moreover, the intersection of Liftago with standard taxi is revealed from the graphical representation. In Ostrava, the unified behaviour of standard taxi and Liftago was revealed from confidence ellipses around categories covering graphical representation of individuals. The nonstandard observation for the group Taxify provider within the Uber is caused by exceptionally used car Volkswagen and rare weekend prevailing days. The exceptional observation for Liftago provider within the Uber is caused by only one car which is not identified from the Liftago group in case of our sample.

\section{Figure 4. Expression of individuals}
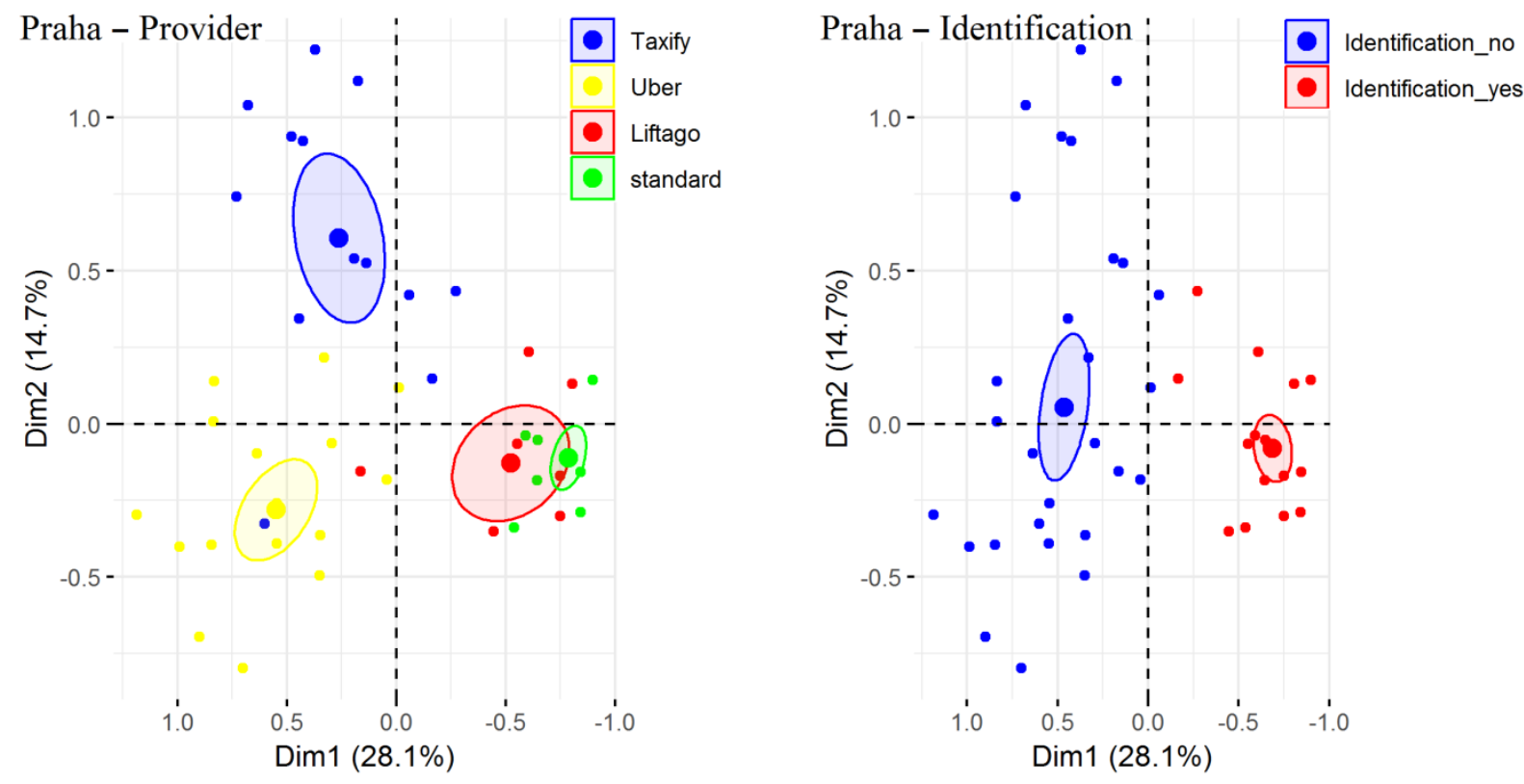

Source: own compilation

This study finds similar results with some researches (Tirachini \& del Rio, 2019; Young \& Farber, 2019; Rayle et al., 2016) since Uber in Prague mostly have had their trips at the weekends. However, the results regarding trips of Liftago oppose to the finding of these studies (Tirachini \& del Rio, 2019; Young \& Farber, 2019; Rayle et al., 2016) because drivers of Liftago in Ostrava mostly have given these services in workdays.

Regarding mileage, the results of this research for Ostrava corroborates with the results of Clewlow \& Mishra, 2017; Schaller, 2018; Henao \& Marshall, 2018; Erhardt et al., 2019; Tirachini \& Gomez-Lobo, 2019). This is because, all these scholars find that vehicle of ride sourcing platforms make higher mileage than traditional taxi services. But in this research, cars of one of ride sourcing platforms namely, Taxify have driven for lower distances than standard taxi services.

The results of this study also show similarities with some studies regarding working period of drivers of Transportation Network Companies (Rayle et al., 2016; Schwieterman \& Smith, 2018). This is because, analysed drivers of Uber in Prague mostly work at the weekends as part time workers. Above 


\section{JOURNAL OF TOURISM AND SERVICES}

Issue 11, volume 20, ISSN 1804-5650 (Online)

www.jots.cz

mentioned studies also prove the fact that majority of ride sourcing platforms' drivers work as part time workers.

The concept of smart cities recently has attracted attention by policy-makers. Smart cities consist of the use of digital and telecommunication technologies for the benefit of the population and business (Alaverdyan, 2018). Smart services offer many benefits for both manufacturing companies as service providers and as well as for their customers (Kanovska, 2018). Ride-hailing services as a part of smart cities could provide a rich source of data for solving problems in transport management (KPMG, 2020). Although socio-economic and environmental benefits of ride sourcing services have highlighted by many researches, these services can cause some problems because of their substitution role for public transport and standard taxi industry. Increases in demand of these services causes rise in the number of Transportation Network Companies' vehicles and this fact creates some problems such as more traffic jam, air pollution and deadheading trips. These issues might be reasons for why ride sourcing activities are not legal in some countries such as Chile (Was before, then became legal), Turkey and some cities in USA (Tirachini \& del Rio, 2019; Bacik et al., 2019). These services also face with limitations regarding their activities in USA and other countries (Brown, 2016; Rosenblat et al., 2017). Except from these implementations of governments, to prevent such disruptive issues, policy makers might direct vehicles of these platforms to play complementary role for public transportation trips that are taken in suburbans with lower traffic jam density.

Policy makers and local authorities might also take some steps to reduce unfair competition between taxi industry and ride sourcing services. These authorities can make some regulations for ride sourcing services by requiring them to have some licenses, certifications and security measures as they do for standard taxi industry. Working hours of these services might be determined by authorities to achieve supply and demand equilibrium so prices of these services might be more affordable. Moreover, to adjust fair prices between traditional taxi industry and ride sourcing services, governments and local authorities might ask drivers of Transportation Network Companies to be taxpayers as standard taxi services have tax liabilities.

Regarding quality of these services, practitioners, owners of these platforms, policy makers, local authorities, governments and other important players in management of these services can ask for some competencies when they hire drivers. Except hiring fluent citizens, governments and practitioners of taxi and ride sourcing services also require drivers to be able to speak a foreign language especially in touristic destinations. Moreover, type of cars, their models, security instructions and other requirements might be specified by these authorities to increase quality of these services.

In this context, Belas at al. (2020) showed in research that the entrepreneurs in the Czech Republic should take into account the moral and ethical consequences of their decisions.

Governments or local authorities also oblige ride sourcing platforms to have offices in cities that these platforms provide transportation services. By doing so, authorities can gain more detailed information about ride sourcing trips and provide more efficient solutions to overcome disruptive activities in transportation industry.

\section{Conclusion}

Emergence of new technologies and devices such as GPS and smartphone has enabled ride sourcing platforms to provide benefits for individuals and make these services to gain competitive power against traditional taxi services. To display some statement of transportation industry in Czech Republic, this paper purposes to compare standard taxi services and some ride sourcing platforms such as Taxify, Uber and Liftago regarding characteristics of their trips (such as distance covered by them, frequency of daily trips), their drivers (manner of work, language fluency) and their vehicles (car manufacturers and identification). To hit this target, 84 responses in Prague and Ostrava were collected for a self- 


\section{JOURNAL OF TOURISM AND SERVICES}

Issue 11, volume 20, ISSN 1804-5650 (Online)

www.jots.cz

administered correctly filled questionnaires. Multiple correspondence analysis was run in R-Software to gain results.

The findings regarding characteristics of travel prove that Uber trips in Prague were usually taken at the weekends, while standard taxi services frequently have trips at workdays. On the other hand, passengers in Ostrava mostly used Liftago's services in workdays with lower mileage, while they mainly travelled by standard services at the weekends with higher mileages.

Corresponding to differences in characteristics of the drivers of analysed transportation providers, majority of Taxify drivers in Prague are not Czech fluent. But, most of drivers of standard services in Ostrava and Prague have fluent Czech language. Moreover, drivers of Uber services do these activities as part-time work, while standard taxi industry has full time employees. When it comes to differences in characteristics of vehicles, Uber and Taxify vehicles in Prague do not have car identification. But standard taxi services have cars with identification. Škoda, Volkswagen, Ford and Audi are commonly used cars by analysed transportation providers.

To minimize differences among transportation providers and disruptive action of them, authorities can give complementary role for ride sourcing services and require some licenses, certifications and security measures from them. Governments can also oblige practitioners and drivers of these platforms to be taxpayer. The characteristics of vehicles and competencies of drivers might be determined by policy makers to increase quality of transportation activities.

Although, this study creates significant values by analysing various features of three different carsharing providers and standard taxi services of the Czech Republic, it has some limitations. This research is only limited with the drivers in two cities of the Czech Republic. Moreover, the number of respondents in this study is not too much. Furthermore, the respondents in Ostrava only work two transportation providers Liftago and traditional taxi services. For these reasons, researchers can collect data from more respondents, different countries and more cities to extend the scope of their studies. Furthermore, they can include more Transport Network Companies for their analyses to present more comprehensive studies.

\section{References}

1. Abdi, H. \& Lynne, J. W. (2010). Principal component analysis. WIREs Computational Statistics, 2(4), 433-459, doi.org/10.1002/wics.101

2. Alaverdyan, D., Kučera, F. \& Horák, M. (2018). Implementation of the Smart City Concept in the EU: Importance of Cluster Initiatives and Best Practice Cases. International Journal of Entrepreneurial Knowledge, 6(1), 30-51. doi.org/10.37335/ijek.v6i1.67

3. Androniceanu, A., Tvaronavičienè, M. (2019). Developing a holistic system for social assistance services based on effective and sustainable partnerships. Administratie si Management Public, 33, 103-118. doi.org/10.24818/amp/2019.33-06.

4. Bacik, R., Kmeco, L., Richard, F., Olearova, M., \& Rigelsky, M. (2019). Marketing Instrument of Improving Hotel Management Service: Evidence of Visegrad Group Countries. Marketing and Management of Innovations, 208-220. doi.org/10.21272/mmi.2019.1-17

5. Belás, J., Khan, K.A., Maroušek, J., \& Rozsa, Z. (2020). Perceptions of the importance of business ethics in SMEs: A comparative study of Czech and Slovak entrepreneurs. Ethics \& Bioetics (in Central Europe), 10(1-2), 96-106. doi: 10.2478/ebce-2020-0010.

6. Bencsik, A., Juhasz, T., Mura, L., \& Csanadi, A. (2019). Impact of Informal Knowledge Sharing for Organizational Operation. Entrepreneurial Business and Economics Review, 7(3), 25-42.

doi.org/10.15678/EBER.2019.070302 


\section{JOURNAL OF TOURISM AND SERVICES}

Issue 11, volume 20, ISSN 1804-5650 (Online)

www.jots.cz

7. Belk, R. (2014). You are what you can access: Sharing and collaborative consumption online. Journal of Business Research, 67(8), 1595-1600. doi.org/10.1016/j.jbusres.2013.10.001

8. Bílková, D. (2017). Clusters of the Czech regions and 31 chosen European countries according to the wage level, wage models and gender wage gap by the Czech regions. 20th AMSE. Applications of Mathematics and Statistics in Economics. International Scientific Conference: Szklarska Poreba, 30 August-3 September 2017. Conference Proceedings Full Text Papers. Wrocław: Wydawnictwo Uniwersytetu Ekonomicznego we Wrocławiu Szklarska, 27-42. doi.org/10.15611/amse.2017.20.03.

9. Brown, A. E. (2018). Ridehail Revolution: Ridehail Travel and Equity in Los Angeles. PhD Thesis. University of California Los Angeles. Retrieved September 9, 2019, from https://escholarship.org/uc/item/4r22m57k

10. Brown, K. V. (2016). Uber Is Facing a Staggering Number of Lawsuits. Splinter News, January 25, 2016. Retrieved September 8, 2019, from http://fusion.net/story/257423/everyone-issuing-uber/

11. Campbell, H. (2015). My Rating System for Uber and Lyft Passengers. The Ride Share Guy, August 31. Retrieved September 9, 2019, from http:/ / therideshareguy.com/my-rating-systemfor-uber-and-lyft-passengers/.

12. Castilla, E. J. (2008). Gender, Race, and Meritocracy in Organizational Careers. American Journal of Sociology, 113(6), 1479-1526. doi.org/10.1086/588738

13. Chen, F., Wu, J., Chen, X. \& Wang, J. (2017). Vehicle kilometers traveled reduction impacts of Transit-Oriented Development: Evidence from Shanghai City. Transportation Research Part D: Transport and Environment, 55, 227-245. doi.org/10.1016/j.trd.2017.07.006

14. Chen, M. K. (2017). Dynamic Pricing in a Labor Market: Surge Pricing and Flexible Work on the Uber Platform. Proceedings of the 2016 ACM Conference on Economics and Computation (EC '16). Association for Computing Machinery, New York, NY, USA, 455. doi.org/10.1145/2940716.2940798

15. Cheng, X., Fu, S. \& De Vreede, G.-J. (2018). A mixed method investigation of sharing economy driven car-hailing services: Online and offline perspectives. International Journal of Information Management, 41, 57-64. doi.org/10.1016/j.ijinfomgt.2018.03.005

16. Clewlow, R. R. \& Mishra, G. S. (2017). Disruptive transportation: The adoption, utilization, and impacts of ride-hailing in the United States. Institute of Transportation Studies, University of California, Davis. Research Report UCD-ITS-RR-17-07.

17. Cohen, A. \& Shaheen, S. (2016). Planning for shared mobility. The American Planning Association. PAS Report 583, $111 \mathrm{p}$.

18. de Souza Silva, L. A., De Andrade, M. O. \& Maia, M. L. A. (2018). How Does The Ride-Hailing Systems Demand Affect İndividual Transport Regulation? Research in Transportation Economics, 69, 600-606. doi.org/10.1016/j.retrec.2018.06.010

19. Enoch, M., Potter, S., Parkhurst, G. \& Smith, M. (2004). INTERMODE: Innovations in Demand Responsive Transport. Department for Transport and Greater Manchester Passenger Transport Executive. Retrieved September 9, 2019, from https://www.academia.edu/7140487/INTERMODE_innovations_in_demand_responsive_tra nsport_final_report 


\section{JOURNAL OF TOURISM AND SERVICES}

Issue 11, volume 20, ISSN 1804-5650 (Online)

www.jots.cz

20. Etminani-Ghasrodashti, R. \& Hamidi, S. (2019). Individuals' Demand for Ride-hailing Services: Investigating the Combined Effects of Attitudinal Factors, Land Use, and Travel Attributes on Demand for App-based Taxis in Tehran, Iran. Sustainability, 11(20), 5755, doi:10.3390/su11205755

21. Grahn, R., Harper, C. D., Hendrickson, C., Qian, Z. \& Matthews, H. S. (2019). Socioeconomic and usage characteristics of transportation network company (TNC) riders. Transportation. doi.org/10.1007/s11116-019-09989-3

22. Hamari, J., Sjöklint, M., \& Ukkonen, A. (2016). The sharing economy: Why people participate in collaborative consumption. Journal of the Association for Information Science and Technology, 67(9), 2047-2059. doi.org/10.1002/asi.23552

23. Henao, A. \& Marshall, W. E. (2018). The impact of ride-hailing on vehicle miles traveled. Transportation, 46, 2173-2194. doi.org/10.1007/s11116-018-9923-2

24. Henao, A. (2017). Impacts of Ridesourcing - Lyft and Uber - On Transportation Including VMT, Mode Replacement, Parking, and Travel Behavior. PhD Thesis, University of Colorado.

25. Henao, A., \& Marshall, W. E. (2017). A framework for understanding the impacts of ridesourcing on transportation. In: Meyer, G. \& Shaheen, S. (Eds.), Disrupting Mobility. Lecture Notes in Mobility. Springer, Cham. doi.org/10.1007/978-3-319-51602-8_13

26. Husson, F., Lê, S. \& Pagès, J. (2009). Exploratory multivariate analysis by example using R. London: Chapman \& Hall/CRC.

27. Hyland, M., Frei, C. \& Mahmassani, H. S. (2017). Flexing service schedules: Assessing the potential for demand-adaptive hybrid transit via a stated preference approach. Transportation Research Part C, 76, 71-89. doi.org/10.1016/j.trc.2016.12.017

28. Kanovska, L. (2018). Smart services and their benefits for manufacturers from a global perspective. Ekonomicko-manazerske spektrum, 12(2), 46-56. doi.org/10.26552/ems.2018.2.4656.

29. Kassambara, A. (2017). Practical guide to principal component methods in R. STHDA.

30. Ključnikov, A., Krajcik, V. \& Vincúrová, Z.. (2018). International sharing economy: The case of airbnb in the Czech Republic. Economics \& Sociology, 11(2). doi.org/10.14254/2071-

789X.2018/11-2/9

31. KPMG (2020). Smart Cities and its relevance to Mobility. KPMG International Cooperative. Retrieved March 20, 2020, fromhttps://assets.kpmg/content/dam/kpmg/za/pdf/pdf2020/smart-cities-and-its-relevanceto-mobility.pdf

32. Le Roux, B. \& Rouanet, H. (2004). Geometric Data Analysis: From Correspondence Analysis to Structured Data Analysis. Dordrecht: Kluwer.

33. Lee, M. K., Kusbit, D., Metsky, E., \& Dabbish, L. (2015). Working With Machines: The Impact of Algorithmic, Data-Driven Management on Human Worker. In Proceedings of the 33rd Annual ACM Conference on Human Factors in Computing Systems (CHI '15). Association for Computing Machinery, New York, NY, USA, 1603-1612. doi.org/10.1145/2702123.2702548

34. McGregor, M., Brown, B., Glöss, M. \& Lampinen, A. (2016). On-Demand Taxi Driving: Labour Conditions, Surveillance, and Exclusion. Paper presented at the 2016 Internet, Policy \& Politics Conferences, Oxford, UK. Retrieved September 10, 2019, from http://blogs.oii.ox.ac.uk/ipp- 


\section{JOURNAL OF TOURISM AND SERVICES}

Issue 11, volume 20, ISSN 1804-5650 (Online)

www.jots.cz

conference/sites/ipp/files/documents/McGregor_Uber\%2520paper\%2520Sept $\% 25201 \% 252$ OPDF.pdf

35. Poliak, M., Poliaková, A., Mrníková, M., Šimurková, P., Jaśkiewicz, M., Jurecki, R. (2017). The Competitiveness of Public Transport. Journal of Competitiveness, 9 (3), 81-97. doi.org/10.7441/joc.2017.03.06

36. Qian, X. \& Ukkusuri, S. V. (2017). Taxi market equilibrium with third-party hailing service. Transportation Research Part B: Methodological, 100, 43-63. doi.org/10.1016/j.trb.2017.01.012

37. Raval, N. \& Dourish, P. (2016). Standing Out From the Crowd: Emotional Labor, Body Labor, and Temporal Labor in Ridesharing. In Proceedings of the 19th ACM Conference on ComputerSupported Cooperative Work \& Social Computing (CSCW'16). Association for Computing Machinery, New York, NY, USA, 97-107. doi.org/10.1145/2818048.2820026

38. Rayle, L., Dai, D., Chan, N., Cervero, R., \& Shaheen, S. (2016). Just a better taxi? A surveybased comparison of taxis, transit, and ridesourcing services in San Francisco. Transport Policy, 45, 168-178. doi.org/10.1016/j.tranpol.2015.10.004

39. Rosenblat, A., \& Stark, L. (2016). Algorithmic Labor and Information Asymmetries: A Case Study of Uber's Drivers. International Journal of Communication, 10, 3758-3784. doi.org/10.2139/ssrn.2686227

40. Rosenblat, A., Levy, K. A. C., Barocas, S. \& Hwang, T. (2017). Discriminating Tastes: Uber's Customer Ratings as Vehicles for Workplace Discrimination. Policy and Internet, 9(3), 256-279. doi.org/10.1002/poi3.153

41. Santi, P., Resta, G., Szell, M., Sobolevsky, S., Strogatz, S. H. \& Ratti, C. (2014). Quantifying the benefits of vehicle pooling with shareability networks. Proceedings of the National Academy of Sciences, 111(37) 13290-13294. doi.org/10.1073/pnas.1403657111

42. Schaller, B. (2018). The New Automobility: Lyft, Uber and the Future of American Cities. New York: Schaller Consulting. Retrieved November 8, 2019, from http://www.schallerconsult.com/rideservices/automobility.pdf

43. Schwieterman, J. \& Smith, C. S. (2018). Sharing the ride: A paired-trip analysis of Uberpool and Chicago Transit Authority services in Chicago, Illinois. Research in Transportation Economics, 71, 9-16. doi.org/10.1016/j.retrec.2018.10.003

44. Sun, L., Teunter, R. H., Babai, M. Z. \& Guowei, H. (2019). Optimal pricing for ride-sourcing platforms. European Journal of Operational Research, 278(3), 783-795.

doi.org/10.1016/j.ejor.2019.04.044

45. Štefko, M. (2019). Notice for reasons of redundancy as a measure for discrimination on grounds of age. Central European Journal of Labour Law and Personnel Management, 1 (1), 61-73. doi.org/10.33382/cejllpm.2019.02.05

46. Tirachini, A. \& del Rio, M. (2019). Ride-hailing in Santiago de Chile: Users' characterisation and effects on travel behaviour. Transport Policy, 82, 46-57.

doi.org/10.1016/j.tranpol.2019.07.008

47. Tirachini, A. \& Gomez-Lobo, A. (2019). Does ride-hailing increase or decrease vehicle kilometers traveled (VKT)? A simulation approach for Santiago de Chile. International Journal of Sustainable Transportation, 14(3), 187-204. doi.org/10.1080/15568318.2018.1539146 


\section{JOURNAL OF TOURISM AND SERVICES}

Issue 11, volume 20, ISSN 1804-5650 (Online)

www.jots.cz

48. Wang, D., Xi, S. \& Gilheany, J. (2015). The Model Minority? Not on Airbnb.com: A Hedonic Pricing Model to Quantify Racial Bias Against Asian Americans. Technology Science. Retrieved November 21, 2019, from http://techscience.org/a/2015090104/

49. Wang, J., Pan, J. \& Li, Y. (2018). The Optimal Strategies of Online Car-hailing Platform Based on The Cost Difference of Drivers. 15th International Conference on Service Systems and Service Management (ICSSSM), Hangzhou, 1-5, doi.org/10.1109/ICSSSM.2018.8464969

50. Young, M. \& Farber, S. (2019). The who, why, and when of Uber and other ride-hailing trips: An examination of a large sample household travel survey. Transportation Research Part A: Policy and Practice, 119, 383-392. doi.org/10.1016/j.tra.2018.11.018

\section{Brief description of Authors:}

\section{Dr. Jiř́i Mezuláník}

Department of Entrepreneurship and Management, Institute of Entrepreneurship and Marketing University of Entrepreneurship and Law

Vltavská 585/14, 15000 Prague, Czech Republic

Web page: www.vspp.cz

E-mail: jiri.mezulanik@vspp.cz

Position: director of institute

The main field of research: sharing economy, communication, marketing.

\section{Lukáš Durda, PhD.}

Department of Entrepreneurship and Management, Institute of Entrepreneurship and Marketing University of Entrepreneurship and Law

Vltavská 585/14, 15000 Prague, Czech Republic

Web page: www.vspp.cz

E-mail: lukas.durda@vspp.cz

Position: senior lecturer and researcher

The main field of research: entrepreneurship, startups, networking.

\section{Mehmet Civelek, Ph.D.}

Department of Entrepreneurship and Management, Institute of Entrepreneurship and Marketing University of Entrepreneurship and Law

Vltavská 585/14, 15000 Prague, Czech Republic

Web page: www.vspp.cz

E-mail: mehmet.civelek@vspp.cz

Position: researcher

The main field of research: entrepreneurship, finance, sharing economy.

\section{Lukáš Malec, Ph.D.}

Head of the Department of Information Technologies and Analytical Methods of the University College of Business in Prague

Spálená 76/14, 11000 Prague, Czech Republic

Web page: www.vso.cz

E-mail: lukas.malec@vso-praha.eu

The main field of research: economic and multivariate statistics. 